\title{
Broncopneumonia em ovino da raça Dorper
}

Leonardo Lomba Mayer, João Gabriel Menezes Daflon, Wagner Ladeira, Aline Emerim Pinna, Mário Felipe Alvarez Balaro, José Aurelino Damasceno Ferreira Filho, Paulo César Amaral Ribeiro da Silva*

Universidade Federal Fluminense (UFF), Niterói, RJ, Brasil

*Autor correspondente

e-mail: pcamaralribeirosilva@id.uff.br

\section{Resumo}

Um ovino da raça Dorper, macho, quatro anos de idade, perda de peso progressiva, alteração comportamental, episódios de tosse seca intermitente e regurgitação, foi encaminhado à Fazenda Escola de Cachoeiras de Macacu da Faculdade de Veterinária da Universidade Federal Fluminense. Exame clínico: ligeira prostração, apetite caprichoso, auscultação pulmonar (estertor e extensas áreas de hiposonoridade). Hemograma: anemia normocítica normocrômica, leucocitose neutrofílica $(13.750 \mathrm{n} / \mu \mathrm{L})$, monocitose $(7 \%)$, linfopenia relativa (20\%), desvio de neutrófilos à direita; OPG sem alterações. Tratado com antibioticoterapia (enrofloxacino $5 \mathrm{mg} / \mathrm{kg}$ nos primeiros 5 dias e 2,5 mg/kg mais 5 dias, SID, IM) e AINE`S. Houve melhora no quadro clínico, porém com tosse seca intermitente. Exame ultrassonográfico da região pulmonar apresentou imagem sugestiva de massa encapsulada na região medial do tórax, entre o $7^{\circ}$ e $8^{\circ}$ espaço intercostal. 0 animal mantinha a alteração comportamental, episódios de tosse seca e regurgitação, escore de condição corporal 3,0, mucosas normocoradas, frequência cardíaca $80 \mathrm{bpm}$, frequência respiratória $36 \mathrm{mrm}$, temperatura $38,2^{\circ} \mathrm{C}$. À palpação, constatou-se aumento na região da faringe e desconforto, com deglutições repetitivas e tosse. À auscultação pulmonar, hiperfonese no pulmão esquerdo. A radiografia lateral da região torácica evidenciou padrão misto (alveolar/nodular) e presença de massa radiopaca (7o espaço intercostal). A radiografia lateral cervical evidenciou dilatação da porção anterior do esôfago, sugestiva de megaesôfago. Oito meses após a remissão clínica e ganho de peso, o animal voltou a apresentar hiporexia e prostração com tosse paroxística. Ao exame clínico, foi verificada hipersonoridade e som áspero nos campos pulmonares, principalmente do lado esquerdo do tórax. Ao exame ultrassonográfico, verificou-se intensa coleção de líquido anecóico na cavidade abdominal e presença de massa encapsulada ecogênica na região caudo-ventral do tórax, próxima ao diafragma. No hemograma, verificou-se uma leucocitose neutrofílica 
discreta (13.450 leucócitos totais $/ \mathrm{mm}^{3}$ ). Devido à recidiva do quadro respiratório e idade avançada, optouse pela eutanásia (ketamina e cloreto de potássio). À necropsia, verificou-se intenso derrame abdominal palha e translúcido (5 litros); hepatomegalia e coloração amarronzada; superfície renal esbranquiçada com aderência de cápsula; pulmão aumentado de tamanho, com áreas difusas de congestão; e presença de massa encapsulada (abscesso) com cerca de $10 \mathrm{~cm}$ adjacente ao bordo ventral do lobo diafragmático esquerdo e abscessos menores presentes no lobo diafragmático e lobo médio direito. Não foram visualizadas alterações macroscópicas no esôfago, conforme previamente verificado pelo laudo radiográfico (megaesôfago), o que sugere uma esofagite, possivelmente traumática. Na histopatologia observou-se broncopneumonia purulenta, glomerulonefrite multifocal não purulenta, necrose hialina intestinal e fibrose periportal com infartos hemorrágicos centro-lobulares (fígado em noz moscada). 